\title{
Vientitukien poistamisen vaikutukset maitosektorille
}

\author{
Meri Virolainen ${ }^{1}$, Panu Kallio ${ }^{1}$ \\ ${ }^{1}$ Pellervon taloudellinen tutkimuslaitos,meri.virolainen@ptt.fi,panu.kallio@ptt.fi
}

Tutkimuksen selvitettiin vientitukien poistamisen vaikutuksia EU:n ja Suomen maitosektorille. Tätä tarkoitusta varten rakennettiin Armington -tyyppinen kaupan osittaistasapaino malli. Tutkimuksen tavoitteena oli selvittää 1) Jos vientituet poistettaisiin WTO-neuvottelujen lopputuloksena, mitä EU:n maitosektorille tapahtuisi tämän jälkeen? 2) Miten Suomen maitosektori sopeutuisi vientitukien muutokseen ja kuinka maitotuotteiden kauppa muuttuisi?

Tutkimuksessa perehdyttiin aluksi kirjallisuuden avulla eri osittaistasapainomalleihin, joita tutkimalla luotiin katsaus mallien teoreettisiin peruslähtökohtiin ja selvitettiin vaihtoehtoisia tapoja mallintaa EU:n maatalouspolitiikka ja WTO:n rajoitteita. Mallityyppien vertailun jälkeen rakennettiin Armington -tyyppinen kaupan osittaistasapainomalli. Tässä simulointimallissa on 7 maata/maaryhmää: Suomi, EU-14 -maat, kahdeksan KIE-maata ja Yhdysvallat, nettoviejät eli NEC ryhmä (Kanada, Uusi Seelanti ja Australia), Venäjä ja muu maailma. Mallia varten kerättiin huomattava määrä dataa. ZMP:ltä saatiin EU-maitomarkkinoita koskevaa dataa, YK:sta ulkomaankauppaan liittyvä Comtrade -dataa, Tullihallitukselta Suomen ulkomaankauppa-aineistoa. Lisäksi aineisto on kerätty lukuisista muista lähteistä. Malli koodattiin lopuksi Exceliin.

Tutkimuksessa käytetyn mallin tulokset voidaan tiivistää seuraavasti. Vientitukien poistolla olisi suhteellisen vähän vaikutusta maidon tuottajahintoihin, vaikka implikaatiot kauppaan olisivat melko suuria. Vientitukien poiston vaikutukset olisivat kuitenkin selvästi suurimmat Suomen maitosektorille, jossa sekä tuottajahinta että maidontuotanto alentuisivat noin $4 \%$. Myös EU-14 -maissa tuottajahinnat ja maidontuotanto vähentyisivät hieman, noin pari prosenttia. Toinen merkittävä tulos oli, että vientitukien poistaminen alentaisi eniten EU-14 -maiden, Suomen ja USA:n maitotuotteiden vientiä. Näin ollen nämä maat myös menettäisivät eniten maitotuotteiden kaupan maailmanmarkkinaosuuksia. Suomen maitotuotteiden viennin määrä sekä viennin arvo alentuisivat noin viidenneksellä. Eniten maitotuotteiden vientitukien poistosta kärsisi rasvattoman maitojauheen ja muiden maitotuotteiden vienti. Vientitukien poistamisen seurauksena NEC -ryhmän maat ja EU:n uudet jäsenmaat hyötyisivät selvästi lisäten markkinaosuuksiaan maitotuotteiden maailmanmarkkinoilla. Tämä on tutkimuksen kolmas keskeinen tulos. NEC -ryhmän maitotuotteiden viennin volyymi lisääntyisi lähes $7 \%$, mutta viennin arvo kasvaisi lähes $15 \%$, koska vientihinnat nousisivat kaikissa tuoteryhmissä. Neljäs merkittävin tulos oli, että maitotuotteiden maailmankauppa vähentyisi vientituen poistettaessa noin $13 \%$. Eniten alentuisi etenkin voin ja muiden maitotuotteiden kauppa. Mallin kahden tärkeimmän tuojan (Venäjä ja muu maailma) tuonti alentuisi noin $15 \%$. Maitotuotteiden maailmankaupan volyymin alentumisesta huolimatta, tuonnin arvo kasvaisi noin $5 \%$. Tämä johtuu tuontihintojen noususta. 


\section{Johdanto}

Maidontuotanto on EU:n maataloustuotannon keskeisin tuotantosuunta. Maidontuotannon arvo on vakiintunut viime vuosina 38 miljardiin euroon, mikä tekee siitä EU:n suurimman yksittäin maataloustuotannon sektorin. Myös maitotuotteiden maailmankaupassa EU on merkittävä tekijä. Maitotuotteiden vienti muodostaa yhteisön maataloustuotteiden kokonaisviennistä noin viidenneksen. Maitotuotteiden vientiä on kuitenkin edistetty vientituilla, koska mm. Uuden Seelannin ja Australian voimakkaat vientiponnistelut ovat nakertaneet EU-maiden tuotteiden kilpailukykyä.

Maidontuotanto on Suomen maataloussektorin tärkein tuotantosuunta. Maitotuotteiden viennillä on myös hyvin merkittävä rooli Suomen maitosektorille, sillä joka kolmas tuotettu litra viedään ulkomaille.

EU:n maitosektori on lähitulevaisuudessa suurten haasteiden edessä. Kansainvälinen maatalousja elintarvikekaupan vapauttaminen on tuonut paineita kauppapolitiikan muuttamiseen myös maitotuotteiden osalta. Vientitukien poistaminen ja markkinoillepääsyn helpottaminen ovat olleet muiden maiden eräitä keskeisimpiä vaatimuksia. Etenkin EU:n vientituen käyttöä on arvosteltu kauppaa vääristävänä tukena. EU on myöntänyt vientitukien käytön ongelmallisuuden, mutta samalla korostanut myös muiden vientitukiin rinnastettavien toimenpiteiden, kuten vienninedistämismaksujen verrattavuutta vientitukiin.

Maailman kauppajärjestön WTO:n käynnissä olevalla kaupan vapauttamiseen pyrkivällä ns. Dohan kehityskierroksella neuvotellaan vientitukien poistamista. Tämän varsin merkittävän toimenpiteen vaikutukset ovat esimerkiksi Suomen maitosektorille todennäköisesti negatiiviset, mutta kvantitatiiviset tutkimukset arvioiden tueksi ovat puuttuneet.

"Vientitukien poistamisen vaikutukset EU:n ja Suomen maitosektorille" -tutkimuksen tarkastelee vientitukien merkitystä Suomen ja EU:n maitosektorille maitomarkkinoiden osittaistasapainomallin avulla. Tutkimuksen tavoitteena oli selvittää 1) Jos vientituet poistettaisiin WTO-neuvottelujen lopputuloksena, mitä EU:n maitosektorille tapahtuisi tämän jälkeen? 2) Miten Suomen maitosektori sopeutuisi vientitukien muutokseen ja kuinka maitotuotteiden kauppa muuttuisi?

Tutkimuksena selvitettiin vientitukien poistamisen vaikutuksia EU:n ja Suomen maitosektoriin kehittämällä maitomarkkinoiden osittaistasapainomalli. Mallin avulla simuloitiin erilaisia skenaarioita, joissa katsottiin politiikkamuutosten vaikutuksia maitosektorille. Tutkimuksessa maitosektoria ja sen erityispiirteitä pyrittiin mallintamaan mahdollisimman realistisesti.

\section{Aineisto ja menetelmät}

Työn ensimmäisessä vaiheessa perehdyttiin kirjallisuuden avulla eri osittaistasapainomalleihin. Mallit käsittelivät joko koko maataloussektoria tai erityisesti vain maitosektoria. Eri osittaistasapainomalleja tutkimalla selvitettiin vaihtoehtoisia tapoja ottaa huomioon mm. EU:n maatalouspolitiikka ja WTOrajoitteet mallintamisessa, koska omassa mallissa pyrittiin mahdollisemman realistiseen maitosektorin ja sen erityispiirteiden mallintamiseen. EU:n maatalouspolitiikan osalta kiinnitettiin huomiota esimerkiksi varastojen ja interventiomekanismin mallintamiseen, ja WTO-rajoitteiden tutkimuksissa selvitettiin mm. rajasuojan mallintamista. Luonnollisesti malleissa kiinnitettiin huomiota myös niiden teoreettisiin peruslähtökohtiin kuten muuttujien endogeeniseen politiikkamallintamiseen ja tuotteiden substituoitavuuteen.

Kirjallisuuskatsauksessa kävi ilmi, että maitosektoria koskevia mallinnuksia on jonkin verran olemassa. Useimmissa oli kuitenkin joitakin sellaisia yksinkertaistavia oletuksia, jotka vaatisivat vielä lisää työstämistä. Malleissa oletettiin usein esimerkiksi ulkomaisten ja kotimaisten vastaavien maitotuotteiden olevan täydellisiä substituutteja keskenään, mikä ei vastaa arkikokemuksia. Toisena ongelmana oli, että ulkomaankauppaa koskevat kauppavirtojen mallirakenteet olivat myös usein melko pelkistettyjä. Kolmantena ongelmana oli se, että mikäli kauppavirtaosiot olivat hyvin yksityiskohtaisesti mallinnettuja, niin EU:n maitosektorin mallinnus oli kovin yksinkertaistettu. Neljäs puute oli se, että Suomi oli monissa tutkimuksissa EU:n osana, jolloin suorien johtopäätösten vetäminen suoraan Suomen maitosektorille oli varsin vaikeaa.

Näitä edellä mainittua ongelmia silmällä pitäen siirryttiin varsinaiseen mallin rakentamisen. Mallin pohjana käytettiin erästä ranskalaista mallia (Bouamra-Mechemache, Chavas, Cox, Réquillart 2002: EU dairy policy reform and future WTO negotiations: A spatial equilibrium analysis), jonka 
EU:n maitosektorin mallitus oli varsin ansiokas. Kauppavirtaosio mallissa oli kuitenkin puutteellinen, joten alkuperäistä mallia modifioitiin jonkin verran alkuperäisestä, jotta se olisi paremmin vastannut tämän tutkimuksen tarkoituksiin. Näin ollen kauppavirtaosiota muutettiin ja laajennettiin, mutta EU:n hyvin yksityiskohtaista maitosektorin mallitusta hieman yksinkertaistettiin eri maiden ja maitotuotteiden osalta.

Tutkimuksessa käytettävä malli on Armington -tyyppinen kaupan osittaistasapainomalli. Tässä simulointimallissa on 7 maata/maaryhmää: Suomi, EU-14 (EU-15 maat pl. Suomi), KIE-8 (EU:n uudet jäsenmaat pois lukien Malta ja Kypros) ja Yhdysvallat, nettoviejät eli NEC (Kanada, UusiSeelanti ja Australia), nettotuojat Venäjä ja muu maailma. Malli määrittää neljälle ensiksi mainitulle maalle/maaryhmälle mm. maidon tuotantomäärät, viiden eri maitotuotteen tuotannot sekä kulutukset ja ulkomaankaupan (lähtömaa ja määränpää mukaan lukien). Nettoviejille ja nettotuojille määritetään viennit ja tuonnit. Malliin on sisällytetty EU:n maatalouspolitiikan instrumentteja kuten interventiomenettely ja maitokiintiöt. Kansallisista tuista myös Suomen maidon hintatuki on mallissa mukana. Markkinoillepääsyä määrittävä tullit on huomioitu sekä luonnollisesti vientituet. Mallissa on viisi eri maitotuoteryhmää: voi, juusto, rasvaton maitojauhe, täysmaitojauhe ja muut maitotuotteet.

Mallin hyvänä puolena voidaan pitää sitä, että se määrittää endogeenisesti maidontuotannon, raakamaidon hinnan sekä maitotuotteiden tuotannot, hinnat, kulutukset, varastot ja ulkomaankaupan. Eri maiden ja maaryhmien keskinäiset kauppavirrat on määritelty erikseen, ja kotimaisia ja ulkomaisia maitotuotteita ei pidetä täydellisinä substituutteina keskenään. Malli huomioi EU:n tärkeimmät maitosektorin politiikkainstrumentit ja ulkokauppaan liittyvät määräykset. Lisäksi politiikkamuutosten vaikutukset nähdään suoraan Suomeen, koska Suomi muodostaa oman ryhmänsä mallissa.

Mallia varten kerättiin huomattava määrä aineistoa. Maitotuotteiden maailmanmarkkinat ovat olleet epävakaita viime vuosina, jonka vuoksi mallin simulointia varten aineistoa kerättiin vuosilta 1999-2001. Tällä pyrittiin saamaan aikaan "keskimääräinen" maitomarkkinatilanne. Yhtä muuttujaa varten tarvittiin siten dataa kaikista maista/maaryhmistä viidelle eri tuotteelle ja kolmelta eri vuodelta. Aineistoa on hankittu lukuisista lähteistä, mutta tärkeimmät on mainittu seuraavassa. Suurin osa tuotanto-, kulutus- ja hintadatasta saatiin ZMP:ltä, kauppaa koskeva data saatiin lähinnä YK:n Comtrade tietokannasta ja FAO:sta sekä Tullihallitukselta Suomen ulkomaankauppaa koskevaa aineistoa. Kauppaan liittyviä tullikiintiö-, tulli- ja vientitukiaineistoa kerättiin monista lähteistä. EU:n market access datapankki, ABARE, AMAD, WTO:n tilastot ja USDA:n tilastot olivat tärkeimmät lähteet. Lisäksi lukuisia muita lähteitä käytettiin aineistokokonaisuuden keräämiseksi.

Mallia varten tarvittiin myös erilaisia joustoja, joita estimointiin osittain itse. Itse estimoidut joustot eivät kuitenkaan lopulta soveltuneet malliin, kun niitä testattiin. Näin ollen päädyttiin kirjallisuudesta otettuihin delphien -menetelmällä saatuihin "konsensus" estimaatteihin, joiden valinnassa kiinnitettiin huomiota etenkin niiden keskinäiseen johdonmukaisuuteen.

Lopuksi malli koodattiin Excel-ohjelmaan, josta ajettiin ensin ns. perusskenaario, joka siis kuvasti todellista tilannetta periodilla 1999-2001. Tämän jälkeen tutkittiin, miten vientitukien poistaminen vaikuttaisi mallin keskeisimpiin muuttujiin.

\section{Tulokset ja tulosten tarkastelu}

Edellä kuvattu osittaistasapainomalli tuottaa suuren määrän informaatiota, mutta mielenkiintoisimmat ja keskeisimmät ajatukset voidaan tiivistää neljään osaan. Lopuksi esitellään tutkimuksen tuottamia yleisiä johtopäätöksiä.

Tutkimuksen mukaan vientitukien poistaminen alentaisi tuottajahintaa Suomessa ja EU-14 -maissa, mutta ei niin paljon kuin joissakin edellisissä tutkimuksissa (esim. ABARE 2001: Impacts of Liberalising World Trade in Dairy Products). Selvästi suurimmat muutokset kohdentuisivat Suomen maitosektorille, jossa sekä tuottajahinta että kokonaismaidontuotanto alentuisivat noin $4 \%$. Myös EU14-maissa tuottajahintojen ja maidontuotanto vähentyisivät hieman, noin pari prosenttia.

Toinen merkittävä tulos oli, että vientitukien poistaminen alentaisi eniten EU-14 -maiden, Suomen ja USA:n maitotuotteiden vientiä. Näin ollen nämä maat myös menettäisivät eniten maitotuotteiden kaupan maailmanmarkkinaosuuksia. Suomen maitotuotteiden viennin määrä sekä viennin arvo alentuisivat noin viidenneksellä (noin 66 milj. dollaria). Eniten maitotuotteiden vientitukien poisto vähentäisi rasvattoman maitojauheen ja muiden maitotuotteiden vientiä, joiden 
viennin volyymi alenisi noin kolmanneksen nykyisestä. Muilla tuotteilla viennin alentuminen jäi noin kymmenen prosentin tienoille.

EU-14:n ja USA:n maitotuotteiden viennin volyymi putoaisi yli viidenneksen, joka merkitsisi EU:lle noin 1,2 miljardin dollarin lovea vientituloissa. Yhdysvalloille maitotuotteiden viennillä on sen sijaan huomattavasti vähemmän merkitystä, jonka vuoksi menetykset USA:n maitosektorin viennille jäisivät noin 250 miljoonan dollarin tienoille. EU-14:n voin vienti romahtaisi lähes kaksi kolmannesta nykyisestä ja myös muiden maitotuotteiden vienti alenisi reilun kolmanneksen nykyisestä. EU:n voin viennin romahtaminen ja muiden maitotuotteiden viennin alentuminen johtuu pitkälti siitä, että näissä tuotteissa vientituen osuus on suhteessa suurin tuotteen hintaan. Myös Yhdysvaltojen viennissä muiden maitotuotteiden vienti romahtaisi yli kaksi kolmannesta, koska myös siellä tämän tuoteryhmän tuen osuus on suhteessa suurin tuotteen hintaan nähden.

Vientitukien poistamisen seurauksena NEC-ryhmän maat ja EU:n uudet jäsenmaat hyötyisivät selvästi lisäten markkinaosuuksiaan maitotuotteiden maailmanmarkkinoilla. Tämä on tutkimuksen kolmas keskeinen tulos. NEC-ryhmän maitotuotteiden viennin volyymi lisääntyisi lähes $7 \%$, mutta viennin arvo kasvaisi lähes $15 \%$, koska vientihinnat nousisivat kaikissa tuoteryhmissä. Näin ollen NEC-ryhmän vientitulot kasvaisivat yli 400 miljoonaa dollaria. Myös EU:n uusien jäsenmaiden viennin volyymi kasvaisi vientitukien poistamisen seurauksena noin $12 \%$, mutta viennin arvo vain $8 \%$, sillä vientihintojen nousu ei olisi niin suurta kuin NEC- mailla. Eniten nämä molemmat maaryhmät lisäisivät muiden maitotuotteiden vientiä.

Neljäs keskeinen tulos oli, että maitotuotteiden maailmankauppa vähentyisi vientituen poistuessa noin $13 \%$. Eniten alentuisi etenkin voin ja muiden maitotuotteiden kauppa. Maitotuotteiden maailmankaupan volyymin alentumisesta huolimatta tuonnin arvo kasvaisi noin $5 \%$. Tämä johtuu ennen muuta siitä, että vientituen poisto nostaisi tuontihintoja. Mallin kahden tärkeimmän tuojaryhmän tuonti alentuisi selvästi. Venäjän tuonti alenisi lähes viidenneksen ja muun maailman lähes $15 \%$.

\section{Johtopäätökset}

Parhaillaan käynnissä olevalla Maailman kauppajärjestön Dohan neuvottelukierroksella neuvotellaan kaupan vapauttamisesta ja etenkin vientitukien poistamisesta, jolla on suurta merkitystä niin EU:n kuin Suomenkin maitosektorille.

Tutkimuksessa käytetyn mallin perusteella voidaan sanoa, että vientitukien poistolla olisi selvästi kustannuksia nostava vaikutus etenkin merkittäville maitotuotteiden tuojamaille. Tuontihintojen nousu vähentäisi näiden maiden tuontia, mutta kasvattaisi silti niiden tuonnista aiheutuvia kustannuksia. Voittajia olisivat sen sijaan NEC-maat ja EU:n uudet jäsenmaat, jotka todennäköisesti lisäisivät vientiään kaikissa tuoteryhmissä. Vanhat EU-maat Suomi mukaan lukien sen sijaan olisivat suurimpia häviäjiä, mitä tulee vientimarkkinaosuuksiin ja maidon tuottajahintoihin.

Suomelle vientitukien poisto ja sitä kautta viennin aleneminen on suhteessa kaikkein haasteellisinta, sillä Suomi vie joka kolmannen tuotetun maitolitran. Siis vaikka muiden EU-maiden vienti alenee suhteessa enemmän kuin Suomen, niin muille EU-maille vienti ei ole yhtä tärkeää kuin Suomelle.

Vientituen alentuminen heijastuu eniten maidon tuottajahintoihin Suomessa. Näin ollen Suomen maitosektorin tilanne, joka näyttää jo EU:n maatalouspolitiikka uudistuksessa kärsineen melko tavalla, näyttää vientitukien poiston myötä muuttuvan yhtä tukalammaksi.

\section{Kirjallisuus}

ABARE 2001. Impacts of Liberalising World Trade in Dairy Products. Written by Ian Shaw and Graham Love. ABARE Research Report 01.4.

Bouamra-Mechemache, Chavas, Cox, Réquillart 2002. EU dairy policy reform and future WTO negotiations: A spatial equilibrium analysis. European Agricultural Economics 2002, 53, 2 